\title{
Quantification of PERF 15 mRNA in Tissue Sections from Rat Testes
}

\author{
Takashi Kogami $^{1}$, Yukari Miki ${ }^{1}$, Teruo Yamada ${ }^{1}$, Teruo Umegaki ${ }^{1}$, \\ Makoto Nishimura $^{1}$, Takashi Amo ${ }^{1}$, Jun Kosaka ${ }^{1}$ and Junzo Sasaki ${ }^{1}$ \\ ${ }^{1}$ Department of Cytology and Histology, Okayama University Graduate School of Medicine, Dentistry and Pharmaceutical \\ Sciences, 2-5-1 Shikatacho, Okayama 700-8558, Japan
}

Received August 7, 2006; accepted November 16, 2006; published online December 22, 2006

\begin{abstract}
We previously conducted basic research to quantify in situ hybridization (ISH) signals in rat testes. In this experimental model, we selected ribosomal RNA (rRNA) as the hybridizable RNA in paraffin sections, since it allowed us to easily analyze ISH signals expressed with digoxygenin (DIG)-labeled probes quantitatively through "posterization" of the images. We applied this method to analyze the quantification of transcript, PERF 15 mRNA. PERF 15 is expressed specifically in the testes and localized in the rigid cytoskeletal structure of the sperm head, and has been considered to be involved in the apoptotic process of spermatogenic cells. Quantification of the signals may help to clarify the detailed function of PERF 15. We further analyzed the signals concomitant with a confocal laser scanning microscope. The peak of PERF 15 mRNA expression was found in diplotene spermatocytes, and the amount of PERF 15 mRNA was greatest in late pachytene and diplotene spermatocytes and early spermatids, followed by early pachytene spermatocytes, and then late spermatids. PERF 15 may be involved in the events leading to meiotic division, in which apoptosis is also involved. The present study may help to determine the concentration of mRNA in tissue sections.
\end{abstract}

Key words: testes, PERF 15, mRNA, in situ hybridization, quantification

\section{Introduction}

We studied the gene expression of reactive oxygen species (ROS)-related enzymes in the reproductive organs using in situ hybridization (ISH) histochemistry and found that hydroperoxide plays important roles in the function of male and female reproductive organs $[20,21,30]$. We hypothesized that the activities of ROS in the reproductive organs were regulated during the estrous cycle and spermatogenesis at the transcriptional level. We therefore tried to estimate the amount of each transcript in certain cell types; however, such estimates tended to be subjective. Next, we performed basic research to quantify the ISH signals in rat testes [14], a suitable organ for the quantification because germ cells undergo synchronized development and show stage-specific

Correspondence to: Junzo Sasaki, M.D., Ph.D., Department of Cytology and Histology, Okayama University Graduate School of Medicine, Dentistry and Pharmaceutical Sciences, 2-5-1 Shikatacho, Okayama 700-8558, Japan. E-mail: sasakij@md.okayama-u.ac.jp gene expression. In this experimental model, a well preserved segment of rRNA [39] was selected as the hybridizable RNA in paraffin sections. Specimens fixed with Bouin's fixative and hybridized with DIG-labeled probes could easily be analyzed quantitatively through "posterization" of the images. The amount of rRNA hybridized with the probe was greatest in the early primary spermatocytes, followed by pachytene spermatocytes, then diplotene spermatocytes and finally secondary spermatocytes and spermatids. The amounts reached low levels in the metaphase, anaphase and telophase of meiotic division and early step 1 spermatids, and then slightly increased during spermiogenesis. ISH rRNA staining [39] was a useful parameter for evaluating the quantitative analysis of mRNA and the levels of hybridizable RNA in tissue sections. In the present study, we applied the method for quantifying the amount of rRNA to the quantification of PERF 15 mRNA. PERF 15, a $15 \mathrm{kDa}$ protein found in the perforatorium of sperm heads [22-25], is identified as a testis lipid-binding protein (TLBP) [32] that is expressed specifically in rat testes although its detailed 
physiological function remains unknown. To investigate the function of PERF 15 in rat testes, we used quantitative analysis of ISH signals. The signals were detected by both the posterization method and fluorescence microscopy using a tyramide signal amplification system.

\section{Materials and Methods}

All animal experiments were performed according to the Guidelines for Animal Experiments of the Okayama University Graduate School of Medicine, Dentistry and Pharmaceutical Sciences. All reagents were of the highest grade commercially available.

\section{Tissue preparation}

Adult male Wistar rats (Clea, Tokyo, Japan), eight weeks old, 200-220 g, were anesthetized by an intraperitoneal injection of pentobarbital $(50 \mathrm{mg} / \mathrm{kg})$. The testes were then perfused with Bouin's fixative and immersed in the same fixative for more than $6 \mathrm{hr}$, dehydrated in ethanol, substituted with xylene, and embedded in paraffin. Paraffin sections (5 $\mu \mathrm{m}$ thick) were mounted on silane-coated slides [31]. Serial sections were mounted on several sets of three slides. The first slide was used for ISH using DIG-labeled probes, the second for PAS staining and the third for ISH using a Tyramide Signal Amplification kit, as described in the Hybridization section. After the experiments, one set of slides was analyzed for the quantification of signals.

\section{Preparation of probes}

To isolate the DNA fragments encoding PERF 15, RTPCR was carried out as described previously $[15,34]$. Total RNA was extracted from rat testes by the acid guanidium thiocyanate-phenol-chloroform extraction method [2]. One set of oligonucleotides (PERF 15-p1 and PERF 15-p2) was used as primers. PERF 15-p1 had the sequence 5'-AGGGAACTGGGAGTGGAATGTGAAC-3', corresponding to nucleotides 83-107 of PERF 15 (TLBP, GenBank accession number U07870) [32]. PERF 15-p2 had the sequence 5'CATCTTTGGATCTGGATCATTGACCC-3', corresponding to nucleotides 287-312. Complementary DNA was synthesized from total RNA of rat testes with a cDNA kit (Takara Biomedical, Shiga, Japan), and the DNA fragments were amplified in a $150 \mu \mathrm{l}$ reaction mixture with a DNA thermal cycler (Astec Co., Fukuoka, Japan) using Taq DNA polymerase in 30 cycles of $30 \mathrm{sec}$ denaturation at $94^{\circ} \mathrm{C}$, $1 \mathrm{~min}$ annealing at $60^{\circ} \mathrm{C}$ and $1 \mathrm{~min}$ synthesis at $72^{\circ} \mathrm{C}$. The purified PCR product was subcloned into the EcoRV site of $p$ Bluescript KS(-). The nucleotide sequence was confirmed using the Sanger dideoxynucleotide-chain termination methods [29]. The same fragment for PERF 15 had been used in the DNA array (B14i: Atlas Rat 1,2, BD Biosciences Clontech, Palo Alto, CA, USA) and its probe specificity had already been confirmed by the manufacturer.

The resultant plasmid DNA was linearized with EcoR I or Hind III. DIG-labeled riboprobes for PERF 15 mRNA were synthesized with an in vitro transcription kit in the presence of T7 or T3 RNA polymerase according to the instructions provided by the manufacturer (Roche Diagnostics Co., Mannheim, Germany). After DNase treatment, the product was ethanol-precipitated and the pellet was resuspended in the hybridization mixture. This probe was used for both Northern blotting and in situ hybridization.

\section{Northern blot analysis}

Messenger RNA was purified from total RNA of rat testes with an Oligotex-dT30 Super mRNA purification kit (Takara Bio, Shiga, Japan). Ten $\mu$ g of poly $(\mathrm{A})^{+}$RNA was separated by electrophoresis in a $1.5 \%$ agarose/formaldehyde gel [28]. The RNA was transferred to Hybond-N ${ }^{+}$ (Amersham Biosciences, Piscataway, NJ, USA) and fixed to the filters by baking at $120^{\circ} \mathrm{C}$ for $15 \mathrm{~min}$. Hybridization was performed at $65^{\circ} \mathrm{C}$ for $16 \mathrm{hr}$ using DIG-labeled cRNA probes in DIG Easy Hyb solution (1603558, Roche Diagnostics Co., Mannheim, Germany). Low stringency washes were followed by a final high-stringency wash in $0.2 \times \mathrm{SSC}$ $(1 \times \mathrm{SSC}=0.15 \mathrm{M} \mathrm{NaCl}, 0.015 \mathrm{M}$ sodium citrate $), 0.1 \%$ sodium dodecyl sulfate at $65^{\circ} \mathrm{C}$ for $30 \mathrm{~min}$. The membrane was treated with RNase and then reacted with an alkaline phosphatase (AP)-conjugated anti-DIG antibody. AP activity was detected using a chemical luminescence method, CDP-Star (Roche Diagnostics Co., Mannheim, Germany).

\section{Hybridization}

Sections were dewaxed with toluene and ethanol, then sequentially treated with $0.2 \mathrm{~N} \mathrm{HCl}, 1 \mu \mathrm{g} / \mathrm{ml}$ proteinase $\mathrm{K}$ in $2 \mathrm{mM}$ of $\mathrm{CaCl}_{2}$ and $20 \mathrm{mM}$ of Tris-HCl buffer (pH 7.5), 2 $\mathrm{mg} / \mathrm{ml}$ glycine in Dulbecco's phosphate buffered saline and acetylated with $0.25 \%$ acetic anhydride in $0.1 \mathrm{M}$ triethanolamine ( $\mathrm{pH} 8.0$ ) to prevent nonspecific binding of the probes. The slides were washed with $2 \times \mathrm{SSC}$ and then prehybridized in a solution containing $50 \%$ formamide and $2 \times \mathrm{SSC}$ at $50^{\circ} \mathrm{C}$ for more than $1 \mathrm{hr}$. Hybridization was performed on slides using $20 \mu \mathrm{l}$ of a hybridization mixture containing 50\% formamide, $2 \times \mathrm{SSC}, 1 \mathrm{mg} / \mathrm{ml}$ tRNA, $0.5 \mathrm{mg} / \mathrm{ml}$ sonicated salmon sperm DNA, $2 \mathrm{mg} / \mathrm{ml}$ bovine serum albumin, $10 \%$ dextran sulfate and the riboprobe (about $2 \mu \mathrm{g} / \mathrm{ml}$ ) at $50^{\circ} \mathrm{C}$ for $16 \mathrm{hr}$ in a moist chamber. The slides were then rinsed three times with $2 \times \mathrm{SSC}$ and $50 \%$ formamide at $50^{\circ} \mathrm{C}$ for $20 \mathrm{~min}$ each and treated with RNase solution.

After further rinsing of the slides with $0.1 \times \mathrm{SSC}$, the detection of signals was performed with two protocols. In the first protocol, an AP-conjugated anti-DIG antibody $(1: 2500)$ was placed on the sections at room temperature for $2 \mathrm{hr}$. After rinsing the slides, the enzyme-catalyzed color reaction was continued overnight with 5-bromo-4-chloro-3indolyl phosphate and nitroblue tetrazolium salt according to the instructions provided with the kit. The sections were stained with methyl green and observed with a light microscope. In the second protocol, a peroxidase-conjugated antiDIG antibody (1:1500) was placed on the sections at $4{ }^{\circ} \mathrm{C}$ overnight. Peroxidase activity was detected using a Tyramide Signal Amplification Kit (TSA DIRECT; NEN Life Science Products-Perkin Elmer, Boston, MA) according to 
the instructions provided with the kit. In brief, a fluorophore-labeled tyramide amplication reagent (TSA-fluorescein) was added at room temperature for $15 \mathrm{~min}$ in a dark room, rinsed and mounted with Slowfade anti-fade reagent (Invitrogen, Carlsbad, CA) [38]. The slides were observed with a Zeiss Confocal Laser Scanning Microscope (LSM510).

\section{Classification of spermatogenesis}

When the stage classification of spermatogenesis in rat testes was investigated, the serial sections were stained with periodic acid Schiff-hematoxylin [8, 27].

\section{Quantification of signals}

In the first protocol, the stained sections were observed under an Axioplan Zeiss microscope using a Plan-Neofluar $20 \times$ lens. Stages of more than 230 tubules were identified in the section, of which five to six tubules per stage were analyzed by the first protocol. Photos obtained with an AxioCam CCD camera were saved in tagged-image file format (TIFF) at a size of $1300 \times 1030$ pixels $(\sim 3.8 \mathrm{MB})$. We saved pictures that included more than four tubules, in which tubules of stage XII-XIII were present, because diplotene spermatocytes always showed strong signals. Images were separated into five tones from dark to light with posterization tools from Adobe Photoshop 5.0 (Adobe Systems; Tucson, AZ). These five tones are expressed as numerals from grade 5 (strongest) to grade 1 (zero intensity): grade 5 black, grade 4 dark grey, grade 3 grey, grade 2 light grey, and grade 1 white. The value in each cell population was obtained and the mean value was expressed in 0.5 intervals as eight gradient densities, 1, 1.5, 2, 2.5, 3, 3.5, 4, 4.5 from white to black (Fig. 4). In the second protocol, the stained sections were observed under an LSM510 using a PlanNeofluar $40 \times / 0.75$ lens. Among the tubules investigated in the first protocol, two to three tubules of Stage V, VI, VII, IX, X and XII-XIII on serial sections were selected, and the signal intensity of more than eight spots in the cytoplasm of each spermatogenic cell (primary and secondary spermatocytes and spermatids) was measured by software for the LSM510 (LSM 5 Image Browser). A histogram of the intensity was obtained from the regions of interest in the cytoplasm, defined by the closed drawing elements and extracted, then converted to tables and transferred to an Excel spreadsheet. The signal intensity was obtained by calculating and expressing it as the mean pixel intensity (0-255) and subtracting the value of the background. The detector gain was sufficiently decreased so that there was only a small amount of pixels showing maximal intensity.

\section{Statistical analysis}

The intensities of the signals in the spermatogenic cells were analyzed by the statistical test described below to compare them with the value of the background and the values of spermatogenic cells at different stages. One way ANOVA was used to examine whether there were any statistical differences among the groups, and then Tukey's HSD multiple comparisons were used to find which pairs of groups were different. Values of $\mathrm{P}<0.05$ were considered significant.

\section{Results}

The specificity of the probe for PERF 15 mRNA was confirmed by Northern blot analysis. When the poly $(\mathrm{A})^{+}$ RNA from the adult rat testes was hybridized with the probe, a single band corresponding to $0.8 \mathrm{~kb}$ was detected (Fig. 1). This result was consistent with a previous report [26]. Therefore, we used this specific probe to localize and quantify PERF 15 mRNA in the ISH study.

Positive signals showing localization of PERF 15 mRNA were detectable in all of the seminiferous tubules when the rat testes were hybridized with an antisense probe (Fig. 2B). A brownish color indicated the gene expression of PERF 15 mRNA. Specific signals were not observed when the rat testes were hybridized with a sense probe (Fig. 2A).

To quantify RNA signals, we ascertained that the signals were distributed evenly among the seminiferous tubules. Four tubules of stages II-III, two of stage V, nine of VII-VIII, two of X-XI, six of stages XII-XIII and five of stage XIV were observed (Fig. 2B). In these tubules, steps 2-3 spermatids in stage II-III, step 5 spermatids in stage V, steps 7-8 spermatids in stage VII-VIII, pachytene spermatocytes in stages $\mathrm{X}-\mathrm{XI}$, and pachytene or diplotene spermatocytes in stages XII-XIII showed equal levels of PERF 15 mRNA expression. In the five tubules of stage XIV, spermatogenic cells showed various levels of PERF 15 mRNA expression according to their phase of mitotic division.

Figures $3 \mathrm{~A}$ and $3 \mathrm{E}$ show high magnification views of

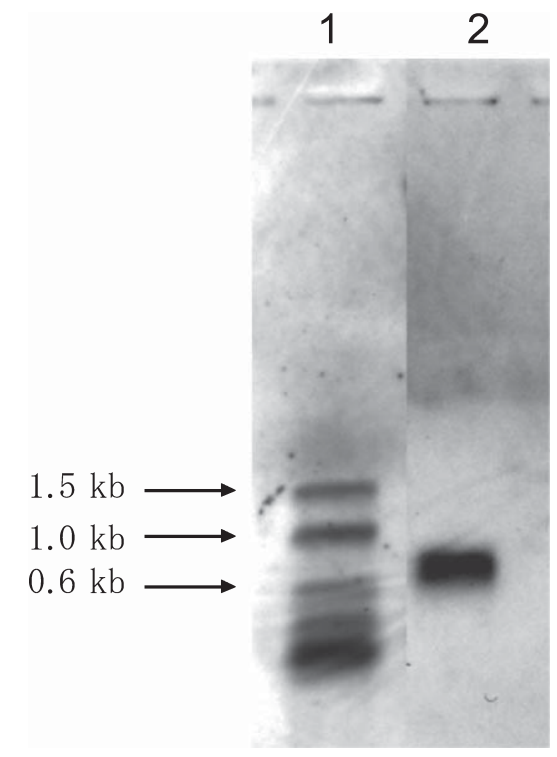

Fig. 1. Northern blot analysis to confirm the probe specificity. When the $10 \mu \mathrm{g}$ of poly $(\mathrm{A})^{+}$RNA from the adult rat testes was hybridized with the PERF $15 \mathrm{cRNA}$ probe, a band of $0.8 \mathrm{~kb}$ was detected (lane 2). No other band was detected in the rat testes. DIGprelabeled markers as a size control (lane 1). 


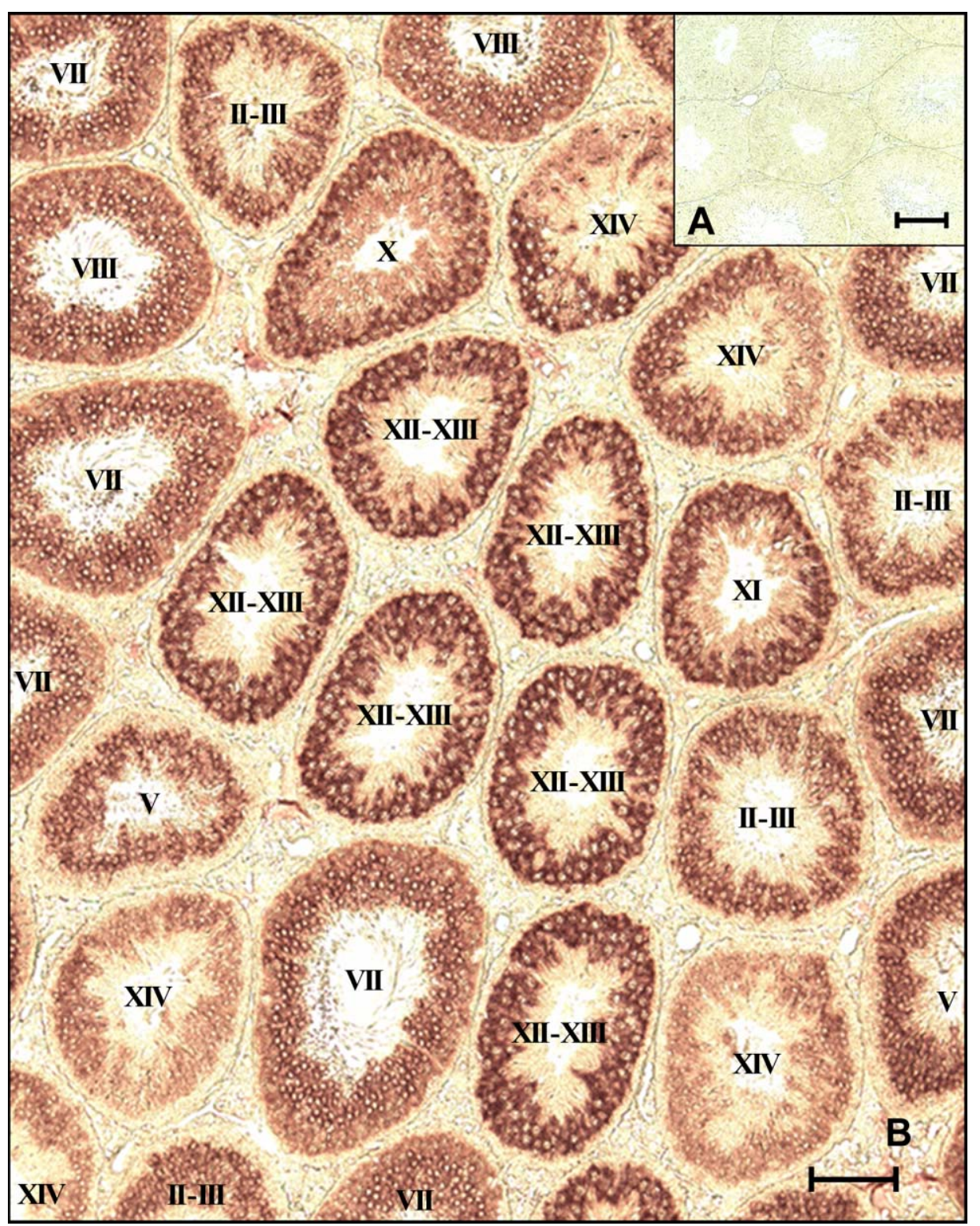

Fig. 2. Detection of PERF 15 mRNA with sense (A) and antisense (B) DIG-labeled probes in rat seminiferous tubules. Roman numerals represent the stages of each seminiferous tubule. Bars $=200 \mu \mathrm{m}(\mathbf{A}), 100 \mu \mathrm{m}(\mathbf{B})$.

the seminiferous tubules hybridized with antisense probes for PERF 15 mRNA. Using a serial section stained with PAS-hematoxylin (Figs. 3D and 3H), the stages in Figures $3 \mathrm{~A}$ and $3 \mathrm{E}$ were identified as II-III, IV, $\mathrm{V}$ and XIV in Fig. 3D and II-III, VIII, X, XII-III and XIV in Fig. 3H.

The expression of PERF 15 mRNA in early pachytene spermatocytes of stages II-III, IV and V (Fig. 3A, arrowheads) was low, but became evident in mid pachytene spermatocytes of stage VIII (Fig. 3E, arrowhead) and marked in late pachytene spermatocytes of stage $X$ and late pachytene and diplotene spermatocytes of stages XII-XIII and XIV (Fig. 3E, arrows). The expression of PERF 15 mRNA was low in the cells exhibiting mitotic division (Figs. 3A and 3E, asterisk). After meiotic division, round spermatids (steps 23, 4, 5 and 8 in Figs. 3A and 3E) maintained high levels of
PERF 15 mRNA expression; however, elongated spermatids (steps 10, 10-12, 14, 16 and 17) decreased their expression as differentiation progressed. Images were separated into five tones from dark to light (Figs. 3B and 3F) and expressed as numerals from grade 5 to grade 1, as described in Materials and Methods. The mean value of each cell population was obtained from five or six tubules and expressed as eight gradient densities, as summarized in Figure 4. The amount of PERF 15 mRNA hybridized with the probe was greatest in the late pachytene and diplotene spermatocytes (grade 44.5 , dark grey to black), followed by early spermatids and mid pachytene spermatocytes (grade 3-3.5, grey), then early pachytene spermatocytes and late spermatids (grade 2.5-1, light grey to white). The amounts reached low levels in the metaphase, anaphase and telophase of meiotic division, and 
then increased during spermiogenesis.

Figures $3 \mathrm{C}$ and $3 \mathrm{G}$ show high magnification images of seminiferous tubules hybridized with antisense probes for PERF 15 mRNA and detected with peroxidase-conjugated anti-DIG antibody and a Tyramide Signal Amplification Kit. Figures $3 \mathrm{~A}, 3 \mathrm{D}$ and $3 \mathrm{C}$, Figures $3 \mathrm{E}, 3 \mathrm{H}$ and $3 \mathrm{G}$ are serial sections (Figs. 3A and 3C, and Figs. 3E and 3G sandwiched Fig. 3D and Fig. 3H, respectively). The PERF 15 mRNA expression pattern in seminiferous tubules detected by the AP-conjugated anti-DIG antibody (Figs. 3A and 3E) was consistent with that detected by the peroxidase-conjugated anti-DIG antibody and a Tyramide Signal Amplification Kit (Figs. 3C and 3G). The signal intensity in the cytoplasm of each spermatogenic cell (primary and secondary spermatocytes and spermatids) was measured as described in Materials and Methods, and the results are summarized in Figure 5. The signal intensities for PERF $15 \mathrm{mRNA}$ in primary spermatocytes and diplotene spermatocytes of stages IX, X and XII-XIII and steps 5-7 spermatids were significantly higher than those of pachytene spermatocytes of stages $\mathrm{V}$ and VII, spermatocytes at metaphase (Me in Fig. 5) and late spermatids (steps 9 and later). However, the results obtained using the second protocol were not completely identical to the results obtained using the first protocol. Although pachytene spermatocytes in stage $\mathrm{X}$ expressed stronger signals than spermatocytes in stage IX or steps 5 and 7 spermatids with the first protocol, there were no significant differences between the signal intensity of stage $\mathrm{X}$ spermatocytes $(141.0 \pm 7.8)$ and those of stage IX spermatocytes $(142.0 \pm 6.4)$, step 5 spermatids $(139.4 \pm 12.1)$ and step 7 spermatids (133.9 \pm 12.9$)$. Intense signals were observed from mid pachytene spermatocytes to round spermatids during spermatogenesis.

\section{Discussion}

\section{Quantification of ISH signals}

We used rat testes for basic research to quantify ISH signals because spermatogenic cells in this organ undergo synchronized development and show stage-specific gene expression, allowing the differences in signal intensities among spermatogenic cell groups to be clearly demonstrated [14]. In that experimental model, we selected a well-preserved segment of rRNA [39] as the hybridizable RNA in paraffin sections and concluded that ISH rRNA staining and the posterization of the signal intensity were useful parameters for the quantitative analysis of mRNA; in other words, for the detection of the total transcriptional activity in the tissue sections. In the present study, we applied this method to the quantification of the transcripts and selected PERF 15 mRNA as the hybridizable RNA because PERF 15 is a novel protein that is expressed specifically in the testes and its physiological function was still unclear. We also used fluorescent signals to quantify the transcripts. Almost the same results were obtained with the two strategies: the posterization of staining intensity (Fig. 4) and quantification of fluorescent signals (Fig. 5). These results support pre- vious data by Oko and Morales [24], in which they stated that the expression of PERF 15 mRNA was apparent in pachytene spermatocytes in stages III and VI, moderate in primary spermatocytes in stages IX and XII, and intense in steps 3 and 6 spermatids, while it was not observed in step 18 spermatids, spermatogonia or leptotene spermatocytes, although the signals using ${ }^{3} \mathrm{H}$-labeled probes did not distinguish among spermatogenic cell groups as did those using DIG-labeled probes.

\section{Localization and function of PERF 15}

The localization and quantity pattern of transcripts led us to consider the importance of PERF 15 in the later stage of meiosis and the early stage of spermiogenesis. The peak of PERF 15 mRNA expression was observed in late pachytene to diplotene spermatocytes at stages XII-XIV just before meiotic division occurred, and was high in round spermatids; this may affect the spontaneous apoptotic process that mostly occurred at stage XIV in physiological spermatogenesis [11] or affect the meiotic process itself.

PERF 15 was originally found in the perinuclear theca of the sperm head $[3,22,25]$. The perinuclear theca is the area that covers the entire nucleus, except for the perifossal zone, and is divided into two distinct parts: the perforatorium, which underlies the acrosomic system, and the basally-located postacrosomal dense lamina. The PERF 15 protein belongs to the components of low-molecular-weight polypeptides and is localized in the thicker apical portion of the perforatorium and the inner zone of the ventral spur. The perforatorium contributes to the shape of the head of the spermatozoon and to the perinuclear theca; both the acrosomic system and cell membrane are tightly bound, keeping the head structure compact, and are considered to be a rigid cytoskeletal structure [3, 22, 24, 25]. PERF 15 is a member of the cellular lipophilic transport protein superfamily that includes adipocyte lipid-binding protein (ALBP), cellular retinoic acid-binding protein (CRABP) or myelin P2. ALBP has been implicated in the uptake and transport of lipids in adipose tissue [37], so PERF 15 may serve similar functions in developing spermatozoa [32].

Recently, Kido and Namiki [12] found strongly PERF 15-positive germ cells at specific stages using immunohistochemistry and showed that TUNEL-positive cells were often high PERF 15 expressers. They reported that exposure to methoxyacetic acid (MAA), known to induce apoptosis in spermatocytes, increased the number of strongly PERF 15positive cells in 25-day-old rat testes, and suggested that the expression of PERF 15 is related to testicular germ cell apoptosis. In transgenic mice that strongly overexpressed PERF 15, programmed cell death occurred at the elongated spermatid stage [13].

In mammalian testes, germ cell apoptosis occurs normally and continuously throughout spermatogenesis $[1,11]$ and works to reduce the number of germ cells and match the supportive capacity of Sertoli cells. We reported that ROS and mitochondrial pathways were involved in the mechanism of tadpole tail disappearance, a typical type of pro- 

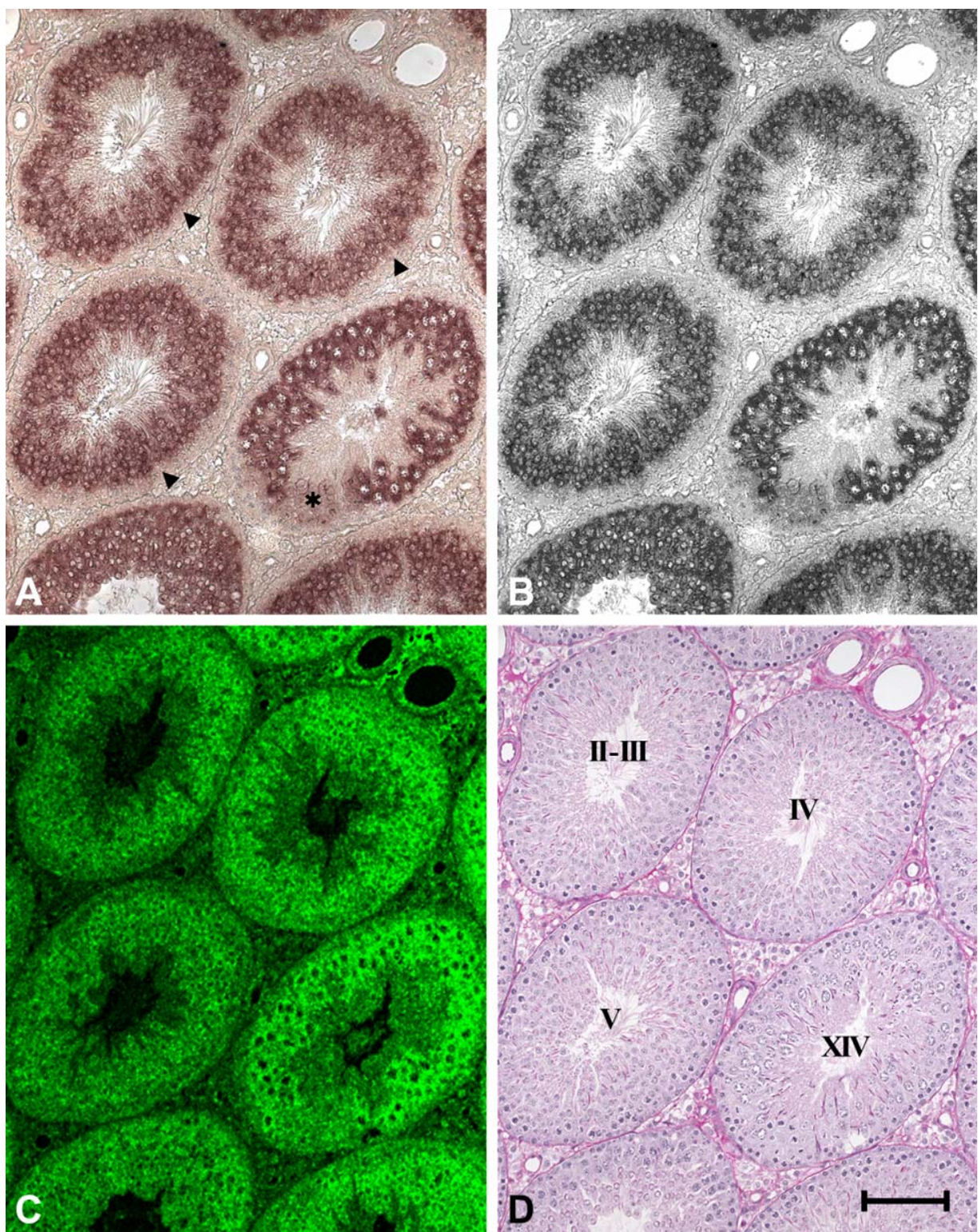

Fig. 3. High magnification of seminiferous tubules showing early stages (A-D, stages XIV, II-III, IV, V) and mid-late stages (E-H, stages VIII, X, XII-XIII, XIV). PERF 15 mRNA in tubules was detected by the anti-DIG-AP system (A and $\mathbf{E})$ and by the anti-DIG-HRP system $(\mathbf{C}$ and $\mathbf{G})$. Images detected in $\mathbf{A}$ and $\mathbf{E}$ were separated into five tones from dark to light in $\mathbf{B}$ and $\mathbf{F}$. D and $\mathbf{H}$ show PAS-hematoxylin stain. Roman numerals represent the stages of each seminiferous tubule. Bar $=100 \mu \mathrm{m}$.

grammed cell death $[6,7,10]$ and di (2-ethylhexyl) phthalate (DEHP)-induced apoptosis in rat testes [9]. The involvement of ROS and a mitochondrial pathway was also reported during estrogen-induced apoptosis in rat testes [19]. The role of PERF 15 in the apoptotic process is not clear, but ROS may be involved, because the testes are rich in lipids. PERF 15 also has a dual function, as Ursini et al. reported in the case of phospholipid hydroperoxide glutathione peroxidase [36]. To clarify the important role of PERF 15 and the involvement of mitochondria or ROS, further analysis of the druginduced apoptotic process in the testes is necessary $[4,9$, 12].

\section{For further quantification of signals}

The measurement of the fluorescent intensity in the present study overcomes several weak points of other efforts to quantify ISH signals. In a previous paper, we described several problems that had been overcome in the quantification of mRNA in tissue sections [14]. These problems were 1) whether or not there was linearity between the probe concentration and the ISH signals, 2) whether or not the number of probe molecules per unit area or per cell cross-section accurately reflected the cellular mRNA content [17], 3) that there were differences in the accessibility of the probes to mRNA among the mRNAs, 4) that the variance in the degree of fixation reflected the degree of accessibility of probes 

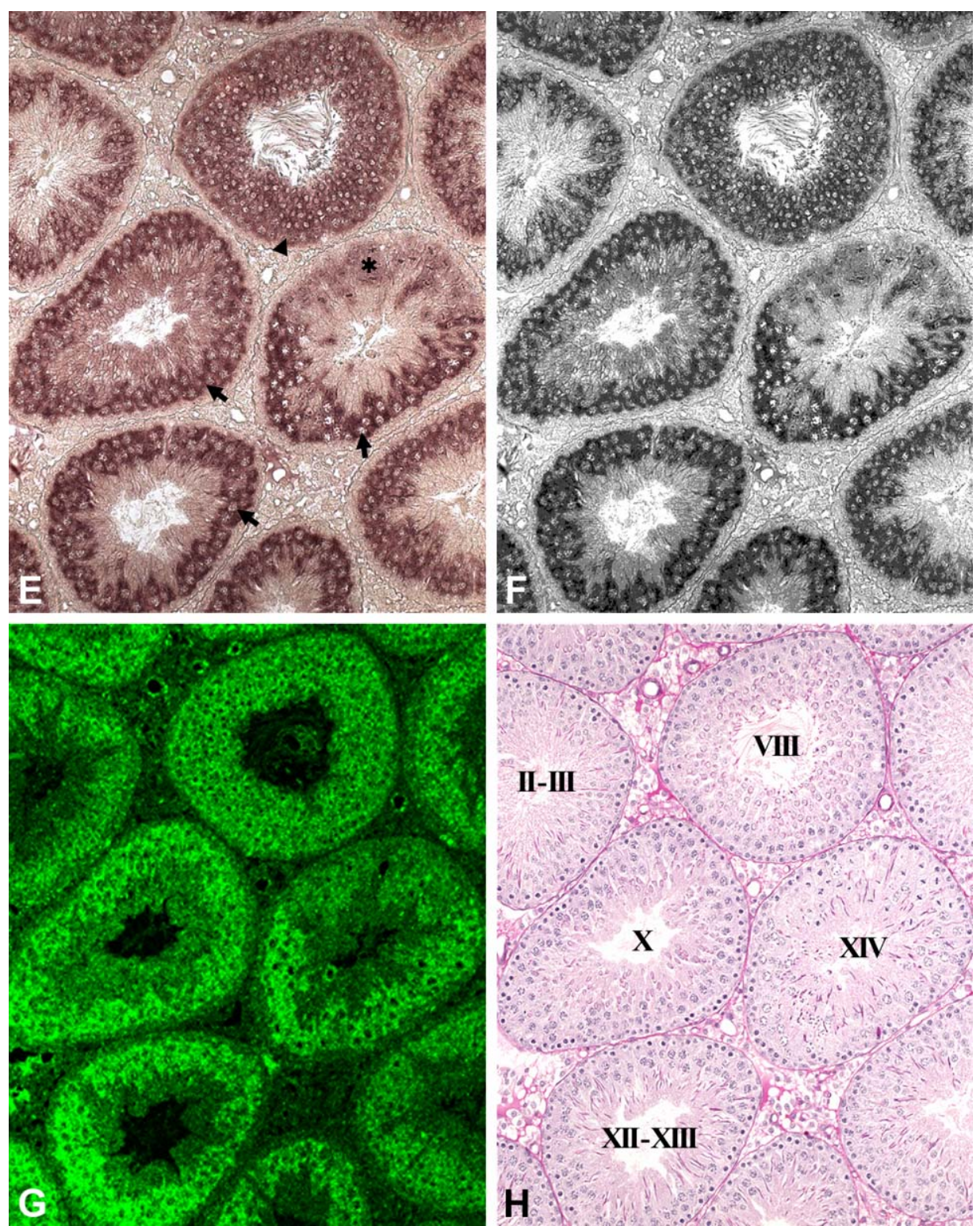

Fig. 3E-H

among different tissue sections [5], and 5) that proteolytic permeabilization depended on the degree of fixation and was critical [16,33], while different cell types often had different optima for permeabilization. Moreover, enzymatic labeling often resulted in the heterogeneous labeling of probe molecules. The 'specific activity' of such probes represented the mean of a wide range of differently labeled probe molecules [16]. The most important problem was that the exact measurement of changes in cell volume, the volume of the structure, or the number of labeled cells was necessary to assess the exact change in the gene expression of a given tissue [18]. The use of confocal laser scanning microscopy may help to solve these problems because it allows us to determine each cell's volume and the cell number, as well as the accessibility of the probes at Z-axis depth with this type of microscopy. Previously, Tsukasaki et al. performed image analysis of the signals detected by DIG-labeled probes and applied the semi-quantification method to the clinical samples [35]. They expressed the amount of the transcript as the ratio to rRNA in the serial section. The present study introduces a fluorochrome-detection system to express the numerical values of the signals, and we showed that similar results were obtained between our method and the posterization one. Tsukasaki et al. spotted DIG-labeled probes for rRNA, from $10^{-12} \mathrm{~g} / \mu \mathrm{l}$ to $10^{-8} \mathrm{~g} / \mu \mathrm{l}$, onto nylon membranes and detected these spots immunohistochemically [35]. By contrast, we made glass slides on which a tissue section and rows of oligonucleotide spots were placed to determine the concentration of mRNA in a tissue section. These spots, 110 $\mu \mathrm{m}$ in diameter, consisted of $1 \mathrm{nl}$ of sense and antisense 


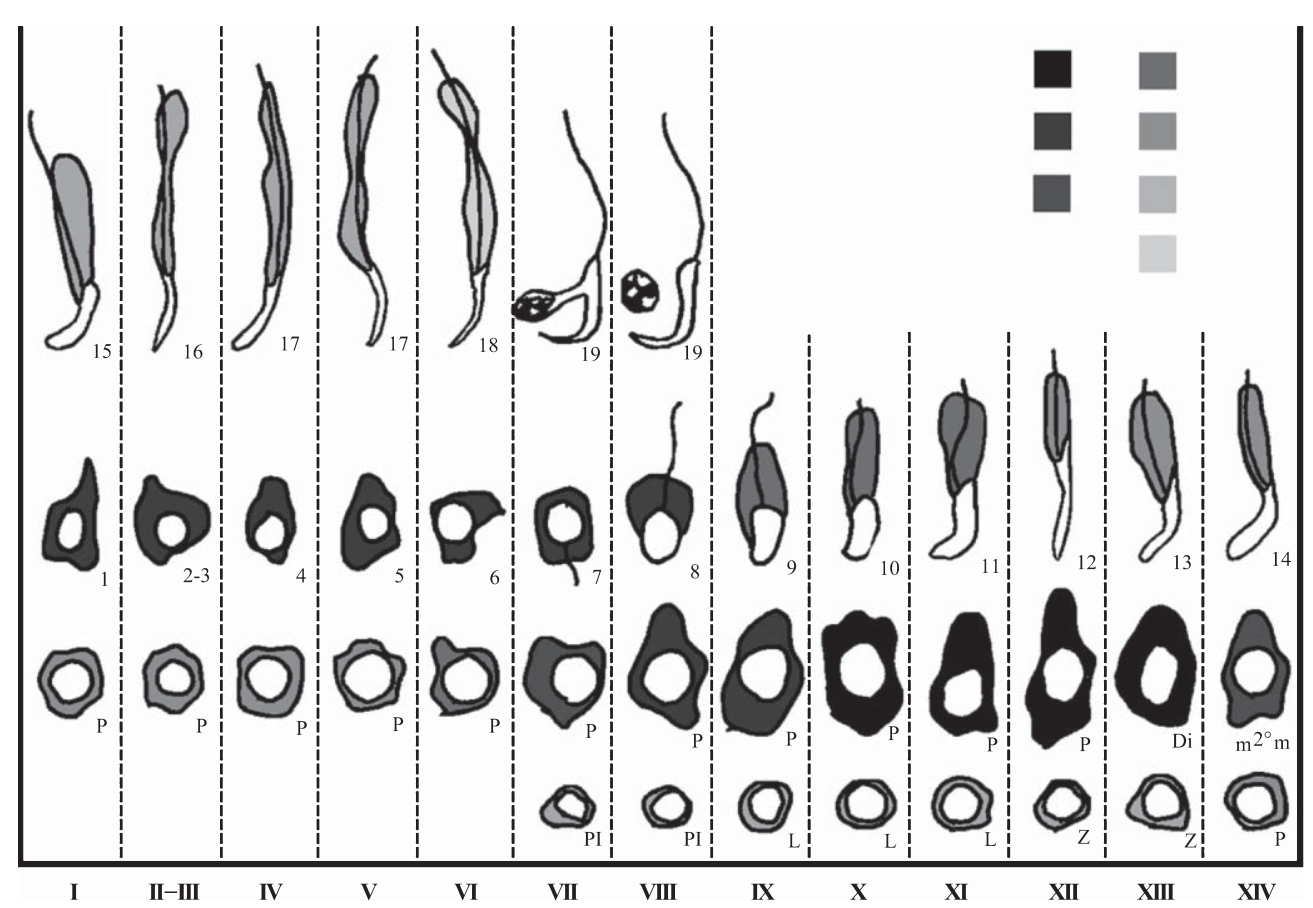

Fig. 4. Quantitative analysis of PERF 15 mRNA detected in the rat seminiferous tubules. The vertical columns numbered with Roman numerals show cell association in cross-sectioned tubules (stages). The developmental progression of a cell is followed horizontally from left to right, and continues from the left of the cycle map one row up. Pl (preleptotene), L (leptotene), Z (zygotene), P (pachytene) and D (diplotene) show the subdivision of the prophase of the first meiotic division. Arabic numerals represent steps of spermatid differentiation. Spermatogonia are not indicated in the cycle map. $2^{\circ} \mathrm{m}$, secondary spermatocytes. Original cyclic map from Russell et al. (1990), with permission.

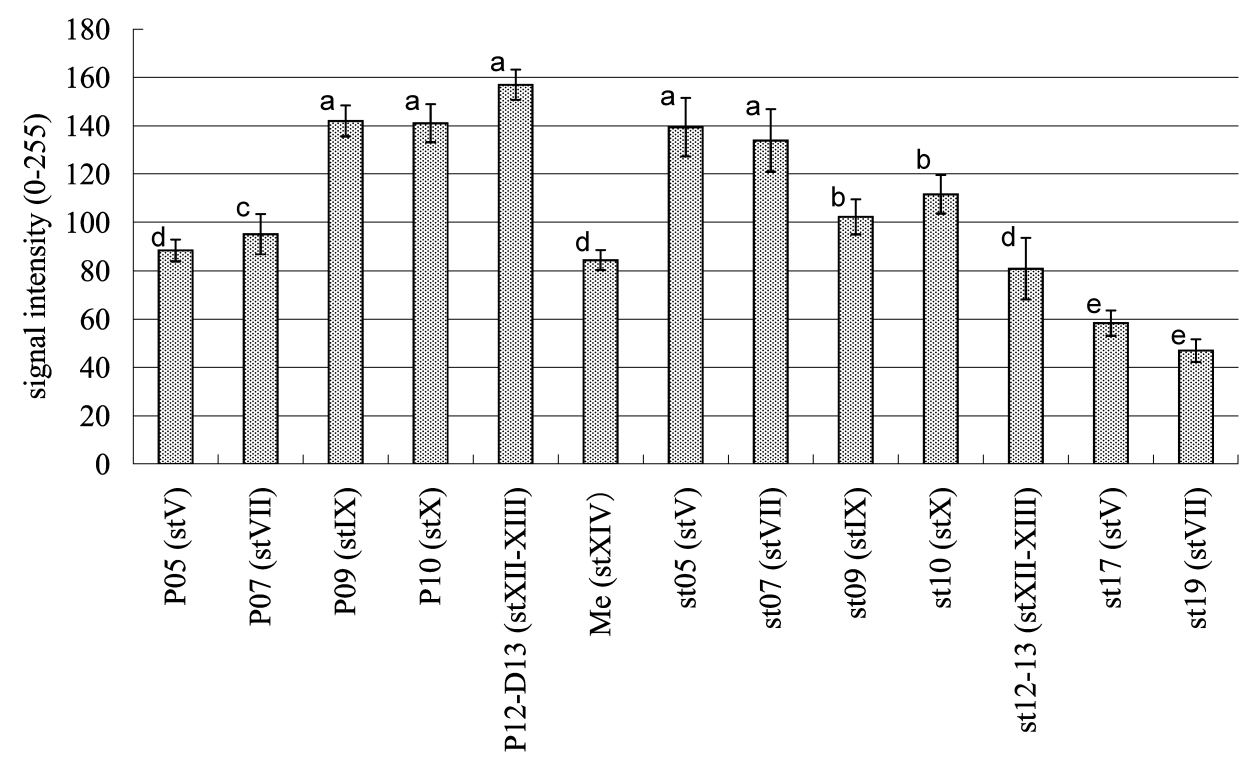

Fig. 5. Quantification of signals. The signal intensity in the cytoplasm of each spermatogenic cell (primary and secondary spermatocytes and spermatids) was measured by LSM 510 software. A histogram of the intensity was obtained from the regions of interest in the cytoplasm, defined by the closed drawing elements and extracted, then converted to tables and transferred to an Excel spreadsheet. The signal intensity was calculated and expressed as the mean pixel intensity $(0-255)$. a: significantly different compared with $b, c, d$ and e $(p<0.05)$. b: significantly different compared with a, $d$ and e $(\mathrm{p}<0.05)$. c: significantly different compared with a and $\mathrm{e}(\mathrm{p}<0.05)$. 
rRNA sequences, from $0-1 \times 10^{-6} \mathrm{M}$ to $500 \mathrm{M}$. We attempted to compare the signal intensity in the tissue section with the signal intensity in the spots containing known concentrations of the given rRNA. The present study may help to establish this method.

In conclusion, we localized and quantified PERF 15 mRNA at the cellular level in the testes. In view of the present results, we suggest that PERF 15 works from the meiotic process to sperm head formation and during apoptotic events in the testes. The quantification of ISH signals may become a powerful tool to define the unknown function of molecules in the postgenomic period.

\section{Acknowledgments}

Supported in part by Grants in Aid for Scientific Research from the Ministry of Education, Culture, Sports, Science and Technology of Japan. We are grateful to Dr. DaHong Wang, Department of Public Health, Okayama University Graduate School of Medicine, Dentistry and Pharmaceutical Sciences for her suggestions regarding statistical analysis and Mr. Shigeto Kanda, Department of Cytology and Histology, Okayama University Graduate School of Medicine, Dentistry and Pharmaceutical Sciences for his technical assistance.

\section{References}

1. Billig, H., Furuta, I., Rivier, C., Tapanainen, J., Parvinen, M. and Hsueh, A. J. (1995) Apoptosis in testis germ cells: developmental changes in gonadotropin dependence and localization to selective tubule stages. Endocrinology 136; 5-12.

2. Chomczynski, P. and Sacchi, N. (1987) Single-step method of RNA isolation by acid guanidinium thiocyanate-phenol-chloroform extraction. Anal. Biochem. 162; 156-159.

3. Clermont, Y., Einberg, E., Leblond, C. and Wagner, S. (1955) The perforatorium - an extension of the nuclear membrane of the rat spermatozoon. Anat. Rec. 121; 1-12.

4. Fujita, H., Ogino, T., Kobuchi, H., Fujiwara, T., Yano, H., Akiyama, J., Utsumi, K. and Sasaki, J. (2006) Cell-permeable cAMP analog suppresses 6-hydroxydopamine-induced apoptosis in PC12 cells through the activation of the Akt pathway. Brain Res. 1113; 10-23.

5. Guiot, Y. and Rahier, J. (1995) The effects of varying key steps in the non-radioactive in situ hybridization protocol: a quantitative study. Histochem. J. 27; 60-68.

6. Hanada, H., Kashiwagi, A., Takehara, Y., Kanno, T., Yabuki, M., Sasaki, J., Inoue, M. and Utsumi, K. (1997) Do reactive oxygen species underlie the mechanism of apoptosis in the tadpole tail? Free Radic. Biol. Med. 23; 294-301.

7. Hanada, H., Katsu, K., Kanno, T., Sato, E. F., Kashiwagi, A., Sasaki, J., Inoue, M. and Utsumi, K. (2003) Cyclosporin A inhibits thyroid hormone-induced shortening of the tadpole tail through membrane permeability transition. Comp. Biochem. Physiol. B. Biochem. Mol. Biol. 135; 473-483.

8. Hess, R. A. (1990) Quantitative and qualitative characteristics of the stages and transitions in the cycle of the rat seminiferous epithelium: light microscopic observations of perfusion-fixed and plastic-embedded testes. Biol. Reprod. 43; 525-542.

9. Kasahara, E., Sato, E. F., Miyoshi, M., Konaka, R., Hiramoto, K., Sasaki, J., Tokuda, M., Nakano, Y. and Inoue, M. (2002) Role of oxidative stress in germ cell apoptosis induced by di(2-ethyl- hexyl)phthalate. Biochem. J. 365; 849-856.

10. Kashiwagi, A., Hanada, H., Yabuki, M., Kanno, T., Ishisaka, R., Sasaki, J., Inoue, M. and Utsumi, K. (1999) Thyroxine enhancement and the role of reactive oxygen species in tadpole tail apoptosis. Free Radic. Biol. Med. 26; 1001-1009.

11. Kerr, J. B. (1992) Spontaneous degeneration of germ cells in normal rat testis: assessment of cell types and frequency during the spermatogenic cycle. J. Reprod. Fertil. 95; 825-830.

12. Kido, T. and Namiki, H. (2000) Expression of testicular fatty acid-binding protein PERF 15 during germ cell apoptosis. Dev. Growth Differ. 42; 359-366.

13. Kido, T., Arata, S., Suzuki, R., Hosono, T., Nakanishi, Y., Miyazaki, J., Saito, I., Kuroki, T. and Shioda, S. (2005) The testicular fatty acid binding protein PERF15 regulates the fate of germ cells in PERF15 transgenic mice. Dev. Growth Differ. 47; $15-24$.

14. Kimura, T., Kosaka, J., Nomura, T., Yamada, T., Miki, Y., Takagi, K., Kogami, T. and Sasaki, J. (2004) Quantification of in situ hybridization signals in rat testes. J. Histochem. Cytochem. 52; 813-820.

15. Kosaka, J., Morii, E., Taniguchi, M., Kitamura, Y., Nomura, S. and Fukuda, Y. (1994) Expression and localization of gammaaminobutyric acid A (GABAA) receptor alpha 1 subunit and Lglutamate decarboxylase (GAD) mRNAs in rat retina: an analysis by in situ hybridization. Brain Res. Mol. Brain Res. 25; 163-167.

16. Larsson, L. I. and Hougaard, D. M. (1990) Optimization of non-radioactive in situ hybridization: image analysis of varying pretreatment, hybridization and probe labelling conditions. Histochemistry 93; 347-354.

17. Larsson, L. I. (1997) Quantitative in situ hybridization. Endocr. Pathol. 8; 3-9.

18. McCabe, J. T. and Bolender, R. P. (1993) Estimation of tissue mRNAs by in situ hybridization. J. Histochem. Cytochem. 41; 1777-1783.

19. Mishra, D. P. and Shaha, C. (2005) Estrogen-induced spermatogenic cell apoptosis occurs via the mitochondrial pathway: role of superoxide and nitric oxide. J. Biol. Chem. 280; 6181-6196.

20. Mori, H., Nomura, T., Seno, M., Miki, Y., Kimura, T., Kogami, T. and Sasaki, J. (2001) Expression of phospholipid hydroperoxide glutathione peroxidase (PHGPx) mRNA in rat testes. Acta Histochem. Cytochem. 34; 25-30.

21. Nomura, T., Sasaki, J., Mori, H., Sato, E. F., Watanabe, S., Kanda, S., Matsuura, J., Watanabe, H. and Inoue, M. (1996) Expression of manganese superoxide dismutase mRNA in reproductive organs during the ovulatory process and the estrous cycle of the rat. Histochem. Cell Biol. 105; 1-6.

22. Oko, R., Moussakova, L. and Clermont, Y. (1990) Regional differences in composition of the perforatorium and outer periacrosomal layer of the rat spermatozoon as revealed by immunocytochemistry. Am. J. Anat. 188; 64-73.

23. Oko, R. and Clermont, Y. (1991) Origin and distribution of perforatorial proteins during spermatogenesis of the rat: an immunocytochemical study. Anat. Rec. 230; 489-501.

24. Oko, R. and Morales, C. R. (1994) A novel testicular protein, with sequence similarities to a family of lipid binding proteins, is a major component of the rat sperm perinuclear theca. Dev. Biol. $166 ; 235-245$.

25. Oko, R. (1995) Developmental expression and possible role of perinuclear theca proteins in mammalian spermatozoa. Reprod. Fertil. Dev. 7; 777-797.

26. Pouresmaeili, F., Morales, C. R. and Oko, R. (1997) Molecular cloning and structural analysis of the gene encoding PERF 15 protein present in the perinuclear theca of the rat spermatozoa. Biol. Reprod. 57; 655-659.

27. Russell, L. D., Ettlin, R. A., Sinha Hikim, A. P. and Clegg, E. D. (1990) Staging for laboratory species. In "Histological and Histopathological Evaluation of the Testis", Clearwater, FL, Cache 
River Press, pp. 62-118.

28. Sambrook, J. and Russell, D. W. (2001) Extraction, purification, and analysis of mRNA from eukaryotic cells. In "Molecular Cloning: A Laboratory Manual, 3rd ed.", New York, U.S.A., Cold Spring Harbor Laboratory Press, pp. 7.1-7.45.

29. Sanger, F., Nicklen, S. and Coulson, A. R. (1977) DNA sequencing with chain-terminating inhibitors. Proc. Natl. Acad. Sci. US A 74; 5463-5467.

30. Sasaki, J., Sato, E. F., Nomura, T., Mori, H., Watanabe, S., Kanda, S., Watanabe, H., Utsumi, K. and Inoue, M. (1994) Detection of manganese superoxide dismutase mRNA in the theca interna cells of rat ovary during the ovulatory process by in situ hybridization. Histochemistry 102; 173-176.

31. Sasaki, J., Yamamoto, H., Nomura, T., Matsuura, J., Seno, M., Sato, E. F. and Inoue, M. (1998) Multiple-labeling of oligonucleotide probes for in situ hybridization. Acta Histochem. Cytochem. $31 ; 275-279$.

32. Schmitt, M. C., Jamison, R. S., Orgebin-Crist, M. C. and Ong, D. E. (1994) A novel, testis-specific member of the cellular lipophilic transport protein superfamily, deduced from a complimentary deoxyribonucleic acid clone. Biol. Reprod. 51; 239-245.

33. Singer, R. H., Lawrence, J. B. and Villnave, C. (1986) Optimization of in situ hybridization using isotopic and non-isotopic deletion methods. BioTechniques 4; 230-250.
34. Suzuki, A., Nomura, S., Morii, E., Fukuda, Y. and Kosaka, J. (1998) Localization of mRNAs for trkB isoforms and $\mathrm{p} 75$ in rat retinal ganglion cells. J. Neurosci. Res. 54; 27-37.

35. Tsukasaki, S., Miyazaki, M., Koji, T., Abe, K., Furusu, A., Shin, M., Suzuki, D., Harada, T., Ozono, Y., Sakai, H. and Kohno, S. (2000) Semi-quantitative non-radioactive in situ hybridization and its clinical application. Acta Histochem. Cytochem. 33; 3947.

36. Ursini, F., Heim, S., Kiess, M., Maiorino, M., Roveri, A., Wissing, J. and Flohe, L. (1999) Dual function of the selenoprotein PHGPx during sperm maturation. Science 285; 1393-1396.

37. Waggoner, D. W. and Bernlohr, D. A. (1990) In situ labeling of the adipocyte lipid binding protein with 3-[125I]iodo-4-azido-Nhexadecylsalicylamide. Evidence for a role of fatty acid binding proteins in lipid uptake. J. Biol. Chem. 265; 11417-11420.

38. Wakabayashi, T., Kosaka, J. and Oshika, T. (2005) JNK inhibitory kinase is up-regulated in retinal ganglion cells after axotomy and enhances BimEL expression level in neuronal cells. J. Neurochem. 95; 526-536.

39. Yoshii, A., Koji, T., Ohsawa, N. and Nakane, P. K. (1995) In situ localization of ribosomal RNAs is a reliable reference for hybridizable RNA in tissue sections. J. Histochem. Cytochem. 43; 321327. 